\title{
High Levels of p19/nm23 Protein in Neuroblastoma Are Associated with Advanced Stage Disease and with $\mathbf{N}$-myc Gene Amplification
}

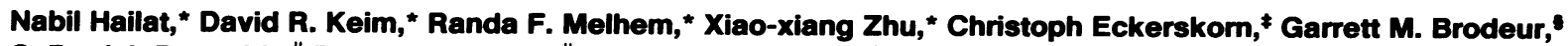 \\ C. Patrick Reynolds," Robert C. Seeger," Friedrich Lottspeich, ${ }^{*}$ John R. Strahler, " and Samir M. Hanash* \\ *University of Michigan Medical School, Department of Pediatric Hematology, R4451 Kresge I, Ann Arbor, Michigan 48109-0510, \\ 'Washington University School of Medicine, Department of Pediatrics, St. Louis, Missouri 63310; "University of Southern California \\ School of Medicine, Children's Hospital of Los Angeles, Department of Pediatrics, Division of Pediatric Hematology/Oncology and \\ Children’s Cancer Study Group, Los Angeles, California 90027; and ${ }^{\ddagger}$ Max Planck Institute for Biochemistry, Munich, West Germany
}

\begin{abstract}
The gene encoding a novel protein designated nm23-H1, which was recently identified as identical to the A subunit of nucleotide diphosphate kinase from human erythrocytes, has been proposed to play a role in tumor metastasis suppression. We report that untreated neuroblastoma tumors contain a cellular polypeptide $\left(M_{\mathrm{r}}=19,000\right)$ designated p19, identified in two-dimensional electrophoretic gels, which occurs at significantly higher levels $(P=0.0001)$ in primary tumors containing amplified $\mathrm{N}$-myc gene. The partial amino acid sequence obtained for p19 is identical to the sequence of the human nm23-H1 protein. An antibody to the A subunit of erythrocyte nucleotide diphosphate kinase reacted exclusively with $p 19$. In this study, signifcantly higher levels of $\mathrm{p} 19 / \mathrm{nm} 23$ occurred in primary neuroblastoma tumors from patients with advanced stages (III and IV) relative to tumors from patients with limited stages (I and II) of the disease. Even among patients with a single copy of the $\mathrm{N}$-myc gene, tumors from patients with stages III and IV had statistically significantly higher levels of p19/nm23 than tumors from patients with stages I and II. Our findings indicate that, in contrast to a proposed role for nm23-H1 as a tumor metastasis suppressor, increased $\mathrm{p} 19 / \mathrm{nm} 23$ protein in neuroblastoma is correlated with features of the disease that are associated with aggressive tumors. Therefore, nm23-H1 may have distinct if not opposite roles in different tumors. ( $J$. Clin. Invest. 1991. 88:341-345.) Key words: neuroblastoma $\bullet N$-myc - NM23 • oncogene • metastasis
\end{abstract}

\section{Introduction}

The discovery in cancer cells of alterations in genes that normally regulate cellular growth and development has encouraged the search for genes that may be responsible for promoting or suppressing tumor spread and metastasis. The protein

Address correspondence to Dr. Samir M. Hanash, Department of Pediatric Hematology, University of Michigan Medical School, R4451 Kresge I, Box 0510, 1500 E. Medical Center Drive, Ann Arbor, MI 48109-0510.

Received for publication 5 March 1991.

J. Clin. Invest.

(c) The American Society for Clinical Investigation, Inc.

0021-9738/91/07/0341/05 \$2.00

Volume 88, July 1991, 341-345 product of the $\mathrm{nm} 23-\mathrm{H} 1$ gene has been proposed as a candidate tumor metastasis suppressor protein $(1,2)$. A strong association was reported between reduced expression of the $\mathrm{nm} 23-\mathrm{H} 1$ gene and acquisition of metastatic behavior. In model systems of rodent metastasis, nm23 RNA levels were lower in highly metastatic cells compared with tumor cells of low metastatic potential (3). Tumors from patients with infiltrating ductal breast carcinomas with lymph node metastasis had low nm23 RNA content (4). Nm23-H1 protein has substantial homology with the polypeptide product of a Drosophila gene, designated awd (5-7), and with a protein in Dictyostelium discoideum, designated GiP17, which exhibits nucleoside diphosphate kinase (NDP) ${ }^{1}$ activity (8). It has recently been shown that the $A$ subunit of NDP kinase in human red cells is identical to nm23$\mathrm{H} 1$, on the basis of sequence analysis (9).

Neuroblastoma is a common childhood tumor that originates in neural-crest derived cells (10). Children with the tumor present with local, regional, or metastatic disease. In clinical studies of neuroblastoma, amplification of the N-myc oncogene has been found to be significantly associated with advanced stage disease and rapid tumor progression (11). The mechanism by which amplification or expression of the N-myc gene alters tumor cell behavior has not been established. We have observed, in a previous study, that neuroblastoma cell lines contained particularly high amounts of a polypeptide, here designated p19, relative to other cell lines analyzed (12). To elucidate the potential significance of p19 in neuroblastoma, we have undertaken a quantitative analysis of this protein in untreated primary neuroblastoma tumors and in neuroblastoma cell lines, following separation of cellular polypeptides by 2-D PAGE (13). The neuroblastoma tumors, as well as the cell lines, contained different copy numbers of the N-myc oncogene. In this study we demonstrate that p19 is identical to $\mathrm{nm} 23-\mathrm{H} 1$ protein and that, in contrast to a proposed role for $\mathrm{nm} 23-\mathrm{H} 1$ as a suppressor of tumor spread, increased p19/ $\mathrm{nm} 23$ protein in neuroblastoma is correlated with features of the disease that are associated with aggressive tumors.

\section{Methods}

Tumors and cell lines. Tumors were obtained from patients at the time of surgery and represented all clinical stages of the disease, from local-

1. Abbreviation used in this paper: NDP, nucleoside diphosphate kinase. 
ized (stage I) to metastatic disease (stage IV). Of the 40 tumors studied for their content of p19, 4 belonged to the special group of infants with metastatic disease (stage IV-S) associated with a very good outcome (10). N-myc gene copy number was determined as previously described (11). The stage IV-S tumors did not show N-myc gene amplification. 15 neuroblastoma cell lines were also analyzed for their p19/nm23 content by 2-D PAGE. 5 cell lines had a nonamplified and 10 had an amplified $\mathrm{N}-m y c$ gene (25-150 copies).

2-D PAGE. Samples of $\sim 200 \mu \mathrm{g}$ of tumor tissue, or of $2 \times 10^{6}$ cells from neuroblastoma cell lines, were solubilized by addition of (per liter) $8 \mathrm{M}$ urea, $20 \mathrm{ml}$ of NP-40 surfactant, $20 \mathrm{ml}$ of ampholytes (pH $3.5-10), 20 \mathrm{ml}$ of 2-mercaptoethanol, and $0.2 \mathrm{mM}$ of PMSF in distilled deionized water. 2-D PAGE was done as previously described (13). In most cases $20-30-\mu l$ aliquots containing $\sim 70 \mu \mathrm{g}$ of protein were immediately applied onto isofocusing gels. First-dimension gels contained 50 $\mathrm{ml}$ of ampholytes per liter ( $\mathrm{pH} 3.5-10$ ). Isofocusing was done at 1,200 $\mathrm{V}$ for $16 \mathrm{~h}$ and $1,500 \mathrm{~V}$ for the last $2 \mathrm{~h}$. 20 gels were run simultaneously. For the second-dimension separation, an acrylamide gradient of 11.4$14.0 \mathrm{~g} / \mathrm{dl}$ was used. Protein spots in gels were visualized using a silverstaining technique (14).

Quantification of p19/nm23. Spot detection and quantitation were performed as previously described (15). Each gel was scanned in a $1,024 \times 1,024$ pixel format, giving $160 \mu \mathrm{m}$ as the pixel width. The digitized images were assigned coded numbers and were analyzed for the presence and quantity of $\mathrm{p} 19 / \mathrm{nm} 23$, without knowledge of the sample to which a gel image corresponded. $\mathrm{P} 19 / \mathrm{nm} 23$ was identified based on its characteristic migration and position in relation to neighboring landmark spots that were present in all gels included in this study and that were recognizable to the analyst. The p19/nm 23 spot, as well as 20 other reference spots, were quantified by placing a cursor on each spot on the graphics monitor and typing in the name for the spot. The integrated intensity of each spot was measured in units of optical density times square millimeter. Data on these spots were analyzed using the Michigan Interactive Data Analysis System, a statistical software package. The 20 reference spots were used to adjust the p19/nm23 spot integrated intensity as previously described (15), to compensate for any variability in protein loading or staining between gels. For comparison of spot intensities between groups, the rank-based KruskalWallis statistic was used rather than parametric tests that require the assumption of Gaussian distributions.

\section{Results}

Relationship between p19 levels and N-myc gene copy number and stage of the disease. Fig. 1 shows representative silverstained 2-D gels of two neuroblastoma tumors, one lacking $\mathrm{N}-m y c$ gene amplification and another with an amplified $\mathrm{N}$ $m y c$ gene. A highly significant difference in p19 levels was observed between tumors containing one $\mathrm{N}-m y c$ gene copy and tumors with more than one copy of the N-myc gene (means for
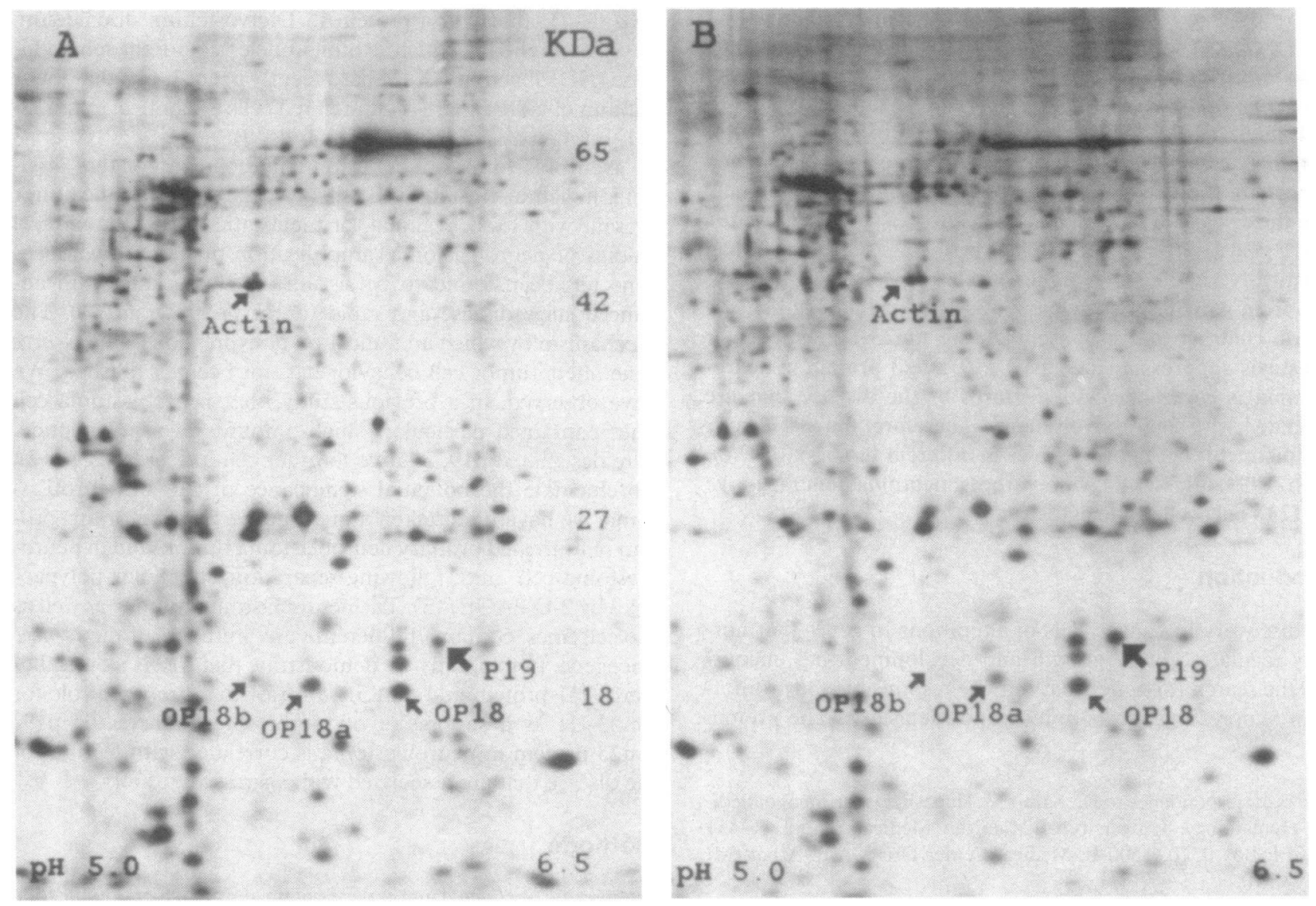

Figure 1. Two-dimensional polypeptide patterns of two neuroblastoma tumors, one with one copy of the N-myc gene (A; patient 15 , Table I) and the other with 125 copies ( $B$; patient 10, Table I), exhibiting a difference in the level of p19. N-myc gene copy number was determined as previously described (3). Phosphorylated forms $(O p 18 a$ and $O p 18 b)$ of a polypeptide, designated Op18, which are diminished with N-myc gene amplification are labeled as a reference (12). N-myc protein is outside of the separation range of the 2-D gels. The pH is indicated on the horizontal axis, and molecular weight is indicated on the vertical axis. The position of actin is indicated by an arrow. 
integrated intensity $=3.29$ vs. $6.11, P=0.0001$ ) (Table I, Fig. 2). The difference in mean integrated intensities corresponds to approximately a fourfold difference in protein amount, based on previous quantitative studies of proteins using 2-D PAGE (15). There was minimal overlap between the amplified and nonamplified groups. Only one tumor in the nonamplified group had a level for p19 that was above the mean for the amplified group. The tumor belonged to the metastatic stage IV. In the amplified group, none of the tumors had a level for p19 that was below the mean in the nonamplified group.

Significant quantitative differences were observed between the levels of p19 in advanced stage (stages III \& IV) and limited stage (stage I \& II) tumors (means $=5.07$ vs. $3.46, P=0.04$ ) (Fig. 2). In advanced stage disease, there was a significant dif-

Table I. P19 Protein Levels in 40 Primary Neuroblastoma Tumors

\begin{tabular}{|c|c|c|c|}
\hline Patient & $\begin{array}{l}\text { Stage of } \\
\text { the disease }\end{array}$ & $\begin{array}{l}\mathrm{N}-m y c \text { gene } \\
\text { copy number }\end{array}$ & P19 \\
\hline 01 & I & 1 & 2.11 \\
\hline 02 & I & 1 & 2.77 \\
\hline 03 & I & 1 & 2.79 \\
\hline 04 & I & 1 & 2.87 \\
\hline 05 & II & 1 & 2.12 \\
\hline 06 & II & 1 & 2.68 \\
\hline 07 & II & 1 & 3.20 \\
\hline 08 & II & 20 & 3.88 \\
\hline 09 & II & 100 & 5.64 \\
\hline 10 & II & 125 & 6.51 \\
\hline 11 & III & 1 & 2.27 \\
\hline 12 & III & 1 & 2.33 \\
\hline 13 & III & 1 & 2.60 \\
\hline 14 & III & 1 & 3.48 \\
\hline 15 & III & 1 & 3.71 \\
\hline 16 & III & 1 & 3.94 \\
\hline 17 & III & 1 & 5.24 \\
\hline 18 & III & 50 & 7.95 \\
\hline 19 & III & 50 & 6.27 \\
\hline 20 & III & 100 & 6.00 \\
\hline 21 & III & 150 & 5.11 \\
\hline 22 & III & 150 & 6.07 \\
\hline 23 & III & 200 & 5.54 \\
\hline 24 & III & 200 & 5.19 \\
\hline 25 & III & 200 & 7.86 \\
\hline 26 & IV & 1 & 3.36 \\
\hline 27 & IV & 1 & 3.57 \\
\hline 28 & IV & 1 & 3.61 \\
\hline 29 & IV & 1 & 3.76 \\
\hline 30 & IV & 1 & 6.21 \\
\hline 31 & IV & 40 & 4.07 \\
\hline 32 & IV & 60 & 6.46 \\
\hline 33 & IV & 150 & 4.54 \\
\hline 34 & IV & 200 & 6.66 \\
\hline 35 & IV & 200 & 12.96 \\
\hline 36 & IV & 300 & 3.36 \\
\hline 37 & IV-S & 1 & 1.76 \\
\hline 38 & IV-S & 1 & 2.91 \\
\hline 39 & IV-S & 1 & 3.10 \\
\hline 40 & IV-S & 1 & 5.21 \\
\hline
\end{tabular}

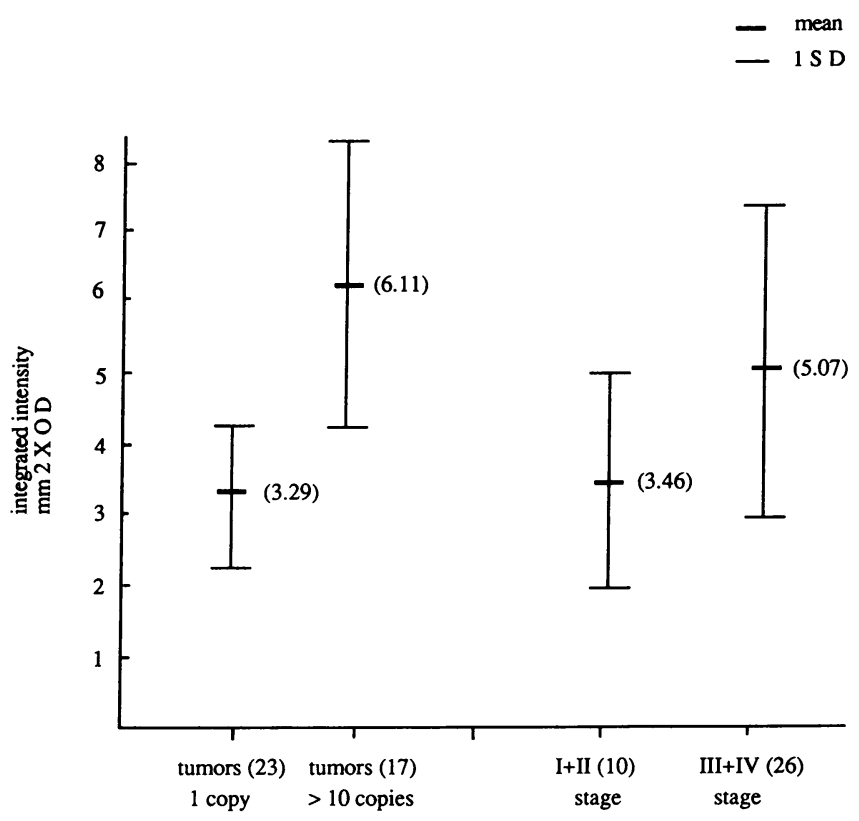

Figure 2. P19 levels in neuroblastoma tumors from patients divided based on $\mathrm{N}-m y c$ gene copy number or stage of the disease. The numbers in parentheses in the $x$ axis indicate the number of tumors analyzed. The numbers in parentheses adjacent to the line plots indicate the means.

ference in the level of $\mathrm{p} 19$ between tumors with nonamplified and tumors with amplified $\mathrm{N}-m y c$ genes (means $=3.69$ vs. $6.27, P=0.001$ ), as was observed for the entire group. There was no significant difference in p19 levels between advanced nonmetastatic (stage III) and advanced metastatic (stage IV) tumors. Also interestingly, the stage IV-S group exhibited a mean p19 level that was equivalent to the mean for the limited stage group (3.25 vs. 3.46). A comparison of the levels of $p 19$ in the nonamplified advanced stage relative to nonamplified limited stage tumors revealed a significant difference between the two groups (means $=3.69$ vs. $2.65, P=0.03$ ). However, the magnitude of the difference was substantially less than when tumors with amplified $\mathrm{N}-m y c$ gene were included in the analysis. Our data therefore indicate that increased levels of p19 in neuroblastoma are associated with $\mathrm{N}-m y c$ gene amplification and with advanced stage disease, independent of $\mathrm{N}-m y c$ gene amplification.

15 neuroblastoma cell lines were analyzed for their p19 polypeptide content. All neuroblastoma cell lines exhibited high levels of p19 (integrated intensities $>3.5$ ). The difference observed in the level of p19 between the nonamplified and the amplified neuroblastoma cell lines (means $=5.73$ vs. 7.91 ) did not reach statistical significance. It should be noted, however, that all neuroblastoma cell lines have been derived from advanced stage tumors.

Identification of p19 as the product of nm 23 gene. Our findings have prompted us to investigate the identity of p19. Proteins in preparative 2-D gels of a neuroblastoma cell line were electroblotted onto glass fiber filters, and p19 spots were excised and applied directly onto a gas phase sequencer (16). While another protein from these blots gave a known sequence, no sequence was generated for p19, suggesting that the $\mathrm{NH}_{2}$ terminus was blocked. This finding led us to pool p19 polypep- 
tide spots from preparative 2-D gels for internal sequencing. Tryptic cleavage fragments were separated by reversed phase HPLC (17). The sequences of three peptides were determined and are shown in Fig. 3. A protein data base search revealed a complete match of the three peptide sequences to $\mathrm{nm} 23-\mathrm{H} 1$ (1), which has been shown to be identical to the A subunit of NDP kinase in human red blood cells (9). Because of the possibility that p19 could represent one of several forms of $n m 23$ protein, this particular form is referred to as $\mathrm{p} 19 / \mathrm{nm} 23$.

Phosphorylation studies. Metabolic labeling of a neuroblastoma cell line with $\left[{ }^{32} \mathrm{P}\right]$ inorganic phosphate was undertaken to determine the phosphorylation status of $\mathrm{p} 19 / \mathrm{nm} 23$. Autoradiographic analysis of 2-D gels revealed absence of a labeled spot in the position of $\mathrm{p} 19$. To rule out the occurrence of other $\mathrm{nm} 23$ related proteins that could be reduced in advanced stage neuroblastoma, we undertook careful quantitative analysis of other proteins in the megawatt range of $15-20 \mathrm{kD}$ in 2-D gels. The only polypeptides observed that were diminished in advanced stage neuroblastoma were unrelated to $\mathrm{nm} 23$ and represented phosphorylated forms of $\mathrm{Op} 18$, as previously reported (18).

Reactivity of p19 with an antibody to NDP kinase. A rabbit polyclonal antiserum against the A subunit of human NDP kinase (kindly provided by Dr. M. Veron, Pasteur Institute, Paris) was used for Western blot analysis of neuroblastoma cell proteins separated by 2-D PAGE. The antiserum was used at a 1,000-fold dilution and reactivity was detected using goat antirabbit peroxidase conjugate. Analysis of samples from several tumors from different stages showed that the antibody preparation reacted strongly and exclusively with the $\mathrm{p} 19$ polypeptide spot. Thus modified forms of p19 such as might result from phosphorylation or cleavage were not detectable.

Southern blot analysis. To determine whether increased $\mathrm{p} 19 / \mathrm{nm} 23$ levels in neuroblastoma tumors are associated with amplification of the nm23 gene, Southern blot analysis of 11 DNA samples from tumors from patients with high or low levels of p19/nm23 was done, using a 600-bp PstI fragment of pnm23, kindly provided by P. Steeg (1). There was no evidence for gene rearrangement or amplification in any of the tumors.

P19 Peptide \# 1 T F I A I K P D G V (Q) R

nm23-H1

nm23-H2S

TFI A I K P D G V Q R

T F I A I K P D G V Q R

40

49

P19 Peptide \# 2

F M (Q) A S E D L L K

nm23-H1

FM Q A SEDLLK

$\mathrm{nm} 23-\mathrm{H} 2 \mathrm{~S}$

FL R ASEEHLK

$89 \quad 94$

P19 Peptide \# 3 V M L GE T

$\mathrm{nm} 23-\mathrm{H} 1$

VMLGET

$\mathrm{nm} 23-\mathrm{H} 2 \mathrm{~S}$
VMLGET
18 sequence of three p19 tryptic peptides purified by reversed phase HPLC. The sequences were determined using a gas phase sequencer (model 470A; Applied Biosystems, Inc., Foster City, CA) as described (7). The corresponding positions of the amino acid residues in the $\mathrm{nm} 23-\mathrm{H} 1$ and $\mathrm{nm} 23-$ $\mathrm{H} 2$ gene sequences are shown.

\section{Discussion}

Our results are in contrast to the reported finding that high metastatic potential tumors, or tumor cell clones, contain more reduced levels of $\mathrm{nm} 23-\mathrm{H} 1$ protein than their low metastatic potential counterparts (1). The data are not directly contradictory, since different types of tumors were studied. Evidence pertaining to an association between low levels of nm23 and metastatic potential were derived from studies of rat fibroblast and melanoma cell lines, rat mammary tumors, and human breast carcinomas $(6,13)$. Also, the possibility exists that $\mathrm{p} 19 / \mathrm{nm} 23$ could be one of several distinct forms of $\mathrm{nm} 23$ that are variably expressed in different cell types and that could play different roles. The initial $\mathrm{nm} 23$ protein sequence was derived from a cDNA clone designated nm23-HI (1). Recently, Stahl et al. have sequenced another cDNA clone, designated nm23-H2, that has led to the identification of a second $\mathrm{nm} 23$ gene, designated $\mathrm{nm} 23-\mathrm{H} 2(19)$. The latter encodes a protein with a predicted $M_{\mathrm{r}}=17,000$, which is $88 \%$ identical to the $\mathrm{nm} 23$ protein sequence derived from $\mathrm{nm} 23-\mathrm{H} 1$. $\mathrm{Nm} 23-\mathrm{H} 2$ is identical to the B subunit of human erythrocyte NDP kinase (9). Nm23-H1 and $\mathrm{nm} 23-\mathrm{H} 2$ RNA levels were determined in a small number of human primary infiltrating ductal breast carcinomas and in human breast tumor cell lines (19). While nm23-H1 RNA levels were reduced several-fold in the metastatic tumors studied, $\mathrm{nm} 23-\mathrm{H} 2$ levels were only slightly reduced (19). Our partial sequence for $\mathrm{p} 19$, which matches the sequence of $\mathrm{nm} 23-\mathrm{H} 1$ but not $\mathrm{nm} 23-\mathrm{H} 2$, together with the observations of unique reactivity of an antibody to human NDP kinase A with p19, clearly indicate that $\mathrm{p} 19$ is identical with $\mathrm{nm} 23-\mathrm{H} 1$ and not $\mathrm{nm} 23-\mathrm{H} 2$.

The discovery of a second $\mathrm{nm} 23$ gene, which, according to Stahl et al. (19), may not be diminished in its expression to the extent $\mathrm{nm} 23-\mathrm{H} 1$ is in certain tumors, does not alter in any way our findings pertaining to the expression of $\mathrm{nm} 23-\mathrm{H} 1$ in neuroblastoma. While we have not identified the polypeptide product of the $\mathrm{nm} 23-\mathrm{H} 2$ gene in neuroblastoma 2-D gels, because of its very basic pI which is outside of the first dimension separation range of 2-D PAGE in this study, we have unequivocally determined that p19 is the product of the $n m 23-\mathrm{H} 1$ gene. The increased expression of this protein in aggressive neuroblastoma tumors would not have been anticipated on the basis of a tumor metastasis suppression role for $\mathrm{nm} 23-\mathrm{H} 1$ and therefore points to another role for this protein.

It is likely that, at least in certain tumors, as in the case of neuroblastoma, $\mathrm{p} 19 / \mathrm{nm} 23$ expression reflects tumor proliferative activity. Proliferating cell nuclear antigen is a component of DNA polymerase $\delta$ that plays an important role in cell proliferation and which we have identified in our 2-D gels (20). We have observed that advanced stage neuroblastoma tumors express increased amounts of proliferating cell nuclear antigen (Keim, D. R., et al., submitted for publication), thus indirectly suggesting a relationship between $\mathrm{p} 19 / \mathrm{nm} 23$ expression and proliferative activity in neuroblastoma. Also, we have observed that human lymphoid cells that were induced to proliferate, exhibited an increase in $\mathrm{p} 19 / \mathrm{nm} 23$ protein level coincident with cell entry into the $S$ phase (Keim, D. R., et al., submitted for publication). In proliferating leukemia cells in culture, a drop in p19/nm23 level was observed with terminal differentiation. Studies by Lacombe et al. (submitted for publication) have shown high NDP kinase activity and high immunoreactivity with an antibody to NDP kinase A, in metastatic carcinomas of breast, colon, and cervix, and in metastatic malig- 
nant melanoma. Their findings are inconsistent with a proposed role for $\mathrm{nm} 23-\mathrm{H} 1$ as a tumor metastasis suppressor and are suggestive of a role for the protein in tumor proliferation (Veron, M., personal communication).

The absence of detectable phosphorylated forms of p19/ $\mathrm{nm} 23$ in 2-D gels is not surprising, since phosphorylated NDP kinase is a reactive intermediate with rapid turnover. Any of the labile phosphate groups are likely to be lost during solubilization and denaturation of the protein, as part of 2-D PAGE. Incubation of cellular extracts in the presence of $\left[{ }^{32} \mathrm{P}\right] \gamma \mathrm{ATP}$, followed by solubilization and electrophoresis of the extracts, failed to result in the appearance of phosphorylated p19/nm23, most likely for the same reasons.

The possibility remains that $\mathrm{nm} 23$, as a kinase that generates GTP, could play a variety of roles depending on other factors which vary between cells and tumors. NDP kinases have been found to be associated with a variety of GTP binding proteins, playing such roles as regulating the polymerization of microtubules and the function of G-proteins in signal transduction (21). Thus, through their involvement in different cellular processes, they could promote cell proliferation as well as other cellular activities.

The findings to date pertaining to $\mathrm{nm} 23$ serve to illustrate the complex nature of the effect that expression of a particular gene could have on cellular processes. Elucidation of the mechanism by which $\mathrm{nm} 23$ could have distinct if not opposite roles in different tumors could contribute to our understanding of some of the complex processes leading to tumor heterogeneity.

\section{Acknowledgments}

We thank R. Kuick and D. Hodge for their help with gel and statistical analysis.

This work was supported in part by grants CA26803 and CA32146 (S. M. Hanash), CA22794 and CA02649 (R. C. Seeger), CA44904 (C. P. Reynolds), and CA39771 and CA01027 (G. Brodeur), from the National Cancer Institute, Department of Health and Human Services.

\section{References}

1. Rosengard, A. M., H. C. Krutzsch, A. Shearn, J. R. Biggs, E. Barker, I. M. Margulies, C. R. King, L. A. Liotta, and P. S. Steeg. 1989. Reduced nm23/awd protein in tumor metastasis and aberrant Drosophila development. Nature (Lond.). 342:177-180.

2. Steeg, P. S. 1989. Search for metastasis suppressor genes. Invasion \& Metastasis. 9:351-359.

3. Steeg, P. S., G. Bevilacqua, L. Kopper, U. P. Thorgeirrson, J. E. Talmadge, L. A. Liotta, and M. E. Sobel. 1988. Evidence for a novel gene associated with low tumor metastatic potential. J. Nat. Cancer Inst. (Bethesda). 80:200-204.
4. Bevilacqua, G., M. E. Sobel, L. A. Liotta, and P. S. Steeg. 1989. Association of low nm23 RNA levels in human primary infiltrating ductal breast carcinomas with lymph node involvement and other histopathological indicators of high metastatic potential. Cancer Res. 49:5185-5190.

5. Dearolf, C. R., E. Hersperger, and A. Shearn. 1988. Developmental consequences of $a w d b 3$, a cell-autonomous lethal mutation of Drosophila induced by hybrid dysgenesis. Dev. Biol. 129:159-168.

6. Dearolf, C. R., N. Tripoulas, J. Biggs, and A. Shearn. 1988. Molecular consequences of $a w d b 3$, a cell-autonomous lethal mutation of Drosophila induced by hybrid dysgenesis. Dev. Biol. 129:169-178.

7. Biggs, J., N. Tripoulas, E. Hersperger, C. Dearolf, and A. Shearn. 1988. Analysis of the lethal interaction between the prune and killer of prune mutations of Drosophila. Genes \& Dev. 2:1333-1343.

8. Nisen, P. D., P. G. Waber, M. A. Rich, S. Pierce, J. R. Garvin, Jr., F. Gilbert, and P. Lanzkowsky. 1988. N-myc oncogene RNA expression in neuroblastoma. J. Nat. Cancer Inst. (Bethesda). 80:1633-1637.

9. Gilles, A.-M., E. Presecan, A. Vonica, and I. Lascu. 1991. Nucleoside diphosphate kinase from human erythrocytes. Structural characterization of the two polypeptide chains responsible for heterogeneity of the hexameric enzyme. $J$. Biol. Chem. In press.

10. Hayes, F. A., and E. I. Smith. 1989. Neuroblastoma. In Principles and Practice of Pediatric Oncology. P. A. Pizzo and D. G. Poplack, editors. J. B. Lippincott, Philadelphia. 607-622.

11. Seeger, R. C., G. M. Brodeur, H. Sather, A. Dalton, S. E. Siegel, K. Y. Wong, and D. Hammond. 1985. Association of multiple copies of the N-myc oncogene with rapid progression of neuroblastoma. N. Engl. J. Med. 313:111116.

12. Hanash, S. M., M. Gagnon, R. C. Seeger, and L. Baier. 1985. Analysis of neuroblastoma cell proteins using two-dimensional electrophoresis. In Advances in Neuroblastoma Research. A. E. Evans, G. J. D'Angio, and R. C. Seeger, editors. Alan R. Liss, Inc., NY. 261-268.

13. Strahler, J. R., R. Kuick, and S. M. Hanash. 1989. Two-dimensional electrophoresis. In Protein Structure: A Practical Approach. T. Creighton, editor. IRL Press Ltd., Oxford. 65-92.

14. Merril, C. R., D. Goldman, S. A. Sedman, and M. H. Ebert. 1981. Ultrasensitive stain for proteins in polyacrylamide gels show regional variation in cerebrospinal fluid. Science (Wash. DC). 211:1437-1438.

15. Kuick, R., S. M. Hanash, E. H. Y. Chu, and J. R. Strahler. 1987. A comparison of some adjustment techniques for use with quantitative spot data from two-dimensional gel. Electrophoresis. 8:199-207.

16. Eckerskorn, C., W. Mewes, H. Goretzki, and F. Lottspeich. 1988. A new siliconized-glass fiber filter as support for protein-chemical analysis of electroblotted proteins. Eur. J. Biochem. 176:509-519.

17. Eckerskorn, C., J. Strahler, S. Hanash, and F. Lottspeich. 1989. Identification and characterization of proteins after 2-D electrophoresis by microsequence analysis demonstrated with leukemia protein markers. In Two-Dimensional Electrophoresis. A. T. Endler and S. M. Hanash, editors. VCH Verlagsgesellschaft, Weinheim, FRG. 153-157.

18. Hailat, N., J. Strahler, R. Melhem, X. X. Zhu, G. Brodeur, R. C. Seeger, C. P. Reynolds, and S. Hanash. 1990. N-myc gene amplification in neuroblastoma is associated with altered phosphorylation of a proliferation related polypeptide. Oncogene. 5:1615-1618.

19. Stahl, J. A., A. Leone, A. M. Rosengard, L. Porter, C. R. King, and P. S Steeg. 1991. Identification of a second human $\mathrm{nm} 23$ gene, nm23-H2. Cancer Res. 51:445-449.

20. Keim, D., N. Hailat, D. Hodge, and S. M. Hanash. 1990. Proliferating cell nuclear antigen/cyclin expression in childhood acute leukemia. Blood. 76:985990

21. Otero, A. D. 1990. Transphosphorylation and G protein activation. Biochem. Pharmacol. 39:1399-1404. 